\title{
Sinomenine, an Antirheumatic Alkaloid, Ameliorates Clinical Signs of Disease in the Lewis Rat Model of Acute Experimental Autoimmune Encephalolmyelitis
}

\author{
Yanying Zeng, ${ }^{a, b}$ Bingjie Gu, ${ }^{a}$ Xiaohui $\mathrm{J}_{\mathrm{I}},{ }^{*, a}$ Xinsheng Ding, ${ }^{*, b}$ Chunjie Song, ${ }^{b}$ and Feichi $\mathrm{Wu}^{c}$ \\ ${ }^{a}$ Department of Immunology, Nanjing Medical University; 140 Hanzhong Road, Nanjing 210029, China: ${ }^{b}$ Department of \\ Neurology, The First Affiliated Hospital of Nanjing Medical University; 300 Guangzhou Road, Nanjing 210029, China: \\ and ${ }^{c}$ Hunan Zengqing Pharmaceutical CO., LTD.; 288 Zengqing Road, Huaihua 41800, China. \\ Received January 11, 2007; accepted May 7, 2007
}

The therapeutic value of an antirheumatic alkaloid, sinomenine (SIN), was investigated in the acute experimental autoimmune encephalomyelitis (EAE) model of multiple sclerosis (MS). SIN is a bioactive alkaloid derived from the Chinese medicinal plant, Sinomenium acutum REHDER \& E. H. WILsON (Family Menispermaceae). Chinese doctors have utilized this plant to treat rheumatic and arthritic diseases for over one thousand years. Experiments in which EAE-induced Lewis rats exhibit an acute monophasic episode of disease demonstrated that SIN is effective in preventing clinical signs of disease. The therapeutic effect on disease activity was observed at preonset administration times and at various doses tested. Consistent with disease activity in vivo, SIN-treated animals have reduced cellular infiltration within the spinal cord along with decreased TNF- $\alpha$ and IFN- $\gamma$ expression levels. SIN can significantly inhibit proliferation response of splenocytes induced by $\mathrm{MBP}_{68-82}$. TNF- $\alpha$ and IFN- $\gamma$, secreted by splenocytes induced by $\mathrm{MBP}_{68-82}$ are inhibited by SIN by dose-dependence manner. The mRNA levels of CC chemokines, RANTES, MIP- $1 \alpha$ and MCP-1, are inhibited in SIN-treated EAE rats. The data in this proof of concept study support the premise that SIN may be a promising new therapeutic intervention in MS.

Key words sinomenine; tumor necrosis factor alpha (TNF- $\alpha$ ); gamma-interferon (IFN- $\gamma$ ); experimental autoimmune encephalomyelitis (EAE); CC chemokine

The alkaloid sinomenine (7,8-didehydro-4-hydroxy-3,7dimethoxy-17-methylmorphinan-6-one, SIN) is a bioactive alkaloid derived from the Chinese medicinal plant, Sinomenium acutum REHDER \& E. H. WILSON (Family Menispermaceae). Chinese doctors have utilized this plant to treat rheumatic and arthritic diseases for over one thousand years. ${ }^{1)}$ Clinical trials done in China demonstrated that the pure alkaloid SIN had significant therapeutic effects for the patients who suffered from rheumatoid arthritis (RA). ${ }^{2}$

RA has been classified as a chronic immune-mediated disease that exhibits overlapping manifestation of inflammatory, abnormal cellular and hormonal immune responses with synovial hyperplasia. SIN had been shown to inhibit lymphocytes proliferation in vitro ${ }^{3)}$ and improve adjuvant arthritis (AA) and antigen-induced arthritis (AIA) in rats. ${ }^{4}$ Recently, SIN was observed inhibiting the expression of cytokines, tumor necrosis factor-alpha (TNF- $\alpha$ ) and gamma-interferon (IFN- $\gamma$ ), as well as the activity of nuclear factor-kappaB $(\mathrm{NF}-\kappa \mathrm{B})$ in adjuvant arthritis (AA) rats. Furthermore SIN has suppressive effects on both Th1 and Th2 immune responses, and Th1 response is more preferentially suppressed by the SIN compared to Th2 response in mice. ${ }^{5)}$

Experimental autoimmune encephalomyelitis (EAE) is a $\mathrm{CD}^{+} \mathrm{T}$ cell-mediated inflammatory demyelinating disease of the central nervous system (CNS) that is commonly used as a model of multiple sclerosis (MS). ${ }^{6}$ The generally accepted concept of pathogenesis in both EAE and MS involves episodes of disease onset that correlate with infiltration of activated leukocytes into the CNS, initiation of effector functions through the cytokine network, and production of histopathological lesions that result in neurological deficiencies. ${ }^{7)}$ Proliferation of $\mathrm{T}$ cells specific for the immunizing antigen and that these antigen-specific cells produce Th1- type cytokines and transfer are believed to play a key role in this process. ${ }^{8)}$ In Lewis rats, MBP derived from guinea pig myelin is highly encephalitogenic. This is because MBP contain amino acid residues in the dominant encephalitogenic epitope for the Lewis rat, myelin basic protein (MBP) fragment 68-82 ( $\left.\mathrm{MBP}_{68-82}\right)$. MS-like immunopathology can be reproduced in Lewis rats. ${ }^{9-11)}$

As $\mathrm{T}$ cell mediated disorders including $\mathrm{AA}$ and EAE, some drugs such as immunoglobulins and an anti-rheumatic drug (TAK-603) protect against arthritis and EAE and that this beneficial effect is associated with a decreased proliferation of $\mathrm{T}$ cells specific for the immunizing antigen. ${ }^{12,13)}$ For the mechanism of the anti-inflammatory and anti-rheumatic effects of SIN, we explore the effects of SIN on EAE.

\section{MATERIALS AND METHODS}

Experimental Animals Female Lewis rats (Vital River, Beijing, China) were maintained in the SPF animal facility at Laboratory Animal Center of Nanjing Medical University under conventional conditions with laboratory chow and water accessible ad libitum. Animals were housed three or four per cage for at least 1 week prior to study. All animal procedures were conducted in complete compliance with the NIH Guide for the Care and Use of Laboratory Animals and approved by Nanjing Medical University IACUC. Paralyzed rats were afforded easier access to food and water to prevent dehydration. Any animal deemed to be in a moribund state during experimental proceedings was humanely euthanized according to NIH guidelines.

EAE Induction Female Lewis rats were used at 8-9 weeks of age. EAE was induced with $100 \mu \mathrm{g} \mathrm{MBP}_{68-82}$ (Sigma-Aldrich, St. Louis, MO, U.S.A.) in emulsion in 


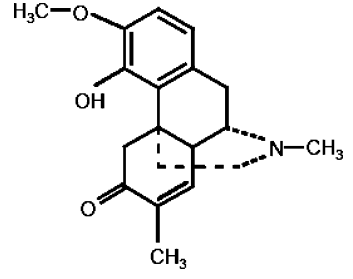

Fig. 1. Chemical Structure of Sinomenine

$100 \mu \mathrm{l}$ of phosphate-buffered saline (PBS) and $100 \mu \mathrm{l}$ of with complete Freund's adjuvant prepared with $4 \mathrm{mg}$ Mycobacterium tuberculosis (Difco, Detroit, MI, U.S.A.) per ml of Incomplete Freund's adjuvant (IFA, Sigma-Aldrich) on day 0 and day 2. A total of $100 \mu \mathrm{l}$ of this emulsion was injected s.c. into the two hind footpads. Controls were immunized only with IFA supplemented with Mycobacterium tuberculosis. Additionally, animals received $200 \mathrm{ng}$ of pertussis toxin on day 0 and 2. Clinical signs in these rats manifest as ascending paralysis resulting in EAE in most animals.

SIN Treatment Procedure SIN was administered i.p. at various doses $(50 \mathrm{mg} / \mathrm{kg}, 100 \mathrm{mg} / \mathrm{kg}$ or $200 \mathrm{mg} / \mathrm{kg}$, respectively) to determine optimum dose. The SIN was provided by National Institute for the Control of Pharmaceutical and Biological Products (Beijing, China), purity was assessed by high performance liquid chromatography (HPLC) $(>95 \%)$. Molecular formula: $\mathrm{C}_{19} \mathrm{H}_{23} \mathrm{NO}_{4}$; molecular weight: 329.38 . CAS registry number: 115-53-7. The molecular structure of SIN is shown in Fig. 1.

SIN dissolved in 2\% dimethyl sulfoxide (DMSO) first, then diluted with PBS for each experiment (the final concentration of DMSO is $0.2 \%$ ). The rats were treated with $0.2 \%$ DMSO or SIN $(50 \mathrm{mg} / \mathrm{kg} / \mathrm{d}, 100 \mathrm{mg} / \mathrm{kg} / \mathrm{d}$ or $200 \mathrm{mg} / \mathrm{kg} / \mathrm{d}$, respectively) with intraperitoneal injection (i.p.) at the day -1 to 3 for 5 consecutive days after immunized. Control rats $(n=12)$ were injected with IFA supplemented with Mycobacterium tuberculosis emulsified with $0.2 \%$ DMSO plus pertussis toxin according to the same schedule (data not shown).

After i.p. administration of SIN $(50 \mathrm{mg} / \mathrm{kg}, 100 \mathrm{mg} / \mathrm{kg}$ or $200 \mathrm{mg} / \mathrm{kg}, n=10$, respectively) or $0.2 \%$ DMSO to EAE rats with 5 consecutive days (day -1 to day 3 ), the plasma concentrations were measured at $\left.250 \mathrm{~min}\left(t_{1 / 2 \mathrm{E}}\right)\right)^{14)}$

Clinical Evaluation Rats ( $n=20$, per group) were observed daily for clinical signs of disease up to $20 \mathrm{~d}$ after immunization. Rat were scored according to their clinical severity with 0.5 points for intermediated clinical findings: grade 0 , no abnormality; grade 0.5 , partial loss of tail tonicity, assessed by inability to curl the distal end of the tail; grade 1, reduced tail tone of slightly clumsy; grade 2, tail atony, moderately clumsy gait, impaired righting ability, or any combination; grade 3 , hide limb weakness of partial paralysis; grade 4, complete hind limb paralysis or fore limb weakness; grade 5 , tetraplegia or moribund state. ${ }^{15}$ ) The data were plotted as daily mean clinical score for all animals in a particular treatment group. Scores for asymptomatic rats $($ score $=0)$ were included in the calculation of the daily mean clinical score for each group. Several parameters of disease were examined to evaluate the severity of EAE and the efficacy of therapy, including mean clinical score, incidence, mean day of onset, disease index, mean maximum severity. ${ }^{16)}$ Moreover, the animals were weighed daily.
Histopathology For histological evidence of EAE, rats from each treatment group were sacrificed at the peak of clinical disease on day 4 post-onset. Animals were deeply anesthetized with nembutal and perfused with $4 \%$ paraformaldehyde. The spinal lumbar part was removed, fixed in 4\% paraformaldehyde and embedded in paraffin for sectioning. A series of spinal cord cross sections were prepared for evaluation of lymphocyte infiltration using hematoxylin and eosin (H\&E) stain. Subsequent analysis of stained tissue sections was done in a blinded fashion by trained investigators. All sections were examined using standard bright-field optics (Zeiss, Axioskop 40). The severity of infiltration was expressed as numbers of perivascular infiltrates per section.

Proliferation Assays and Cytokine Analysis Splenocytes were obtained from each animal group (Control, EAE, $\mathrm{EAE}+\mathrm{SIN} ; n=8$, per group) $7 \mathrm{~d}$ after $\mathrm{MBP}_{68-82}$ sensitization under aseptic conditions, in Hank's balanced salt solution (HBSS, Sigma), minced using a pair of scissors and passed through a fine steel mesh to obtain a homogeneous cell suspension, and the erythrocytes were lysed with ammonium chloride $(0.8 \%, \mathrm{w} / \mathrm{v})$. After centrifugation $\left(380 \times \boldsymbol{g}\right.$ at $4{ }^{\circ} \mathrm{C}$ for $10 \mathrm{~min})$, the pelleted cells were washed three times in PBS, and resuspended in complete medium [RPMI 1640 (Invitrogen, Carlsbad, CA, U.S.A.) supplemented with $12 \mathrm{~mm}$ HEPES (pH 7.1), $50 \mu \mathrm{M}$ 2-mercaptoethanol (Sigma-Aldrich), and $10 \%$ FCS (Invitrogen)]. Cell numbers were counted with a haemocytometer by trypan blue dye exclusion technique. Cell viability exceeded $95 \%$. Then the cells were dissociated into single-cell suspension, and cultured for proliferation assays in flat-bottomed, 96-well microtiter plates (Falcon; BD) at a density of $5 \times 10^{6}$ viable cells per well in a total volume of $200 \mu \mathrm{l}$ RPMI-1640 medium (Invitrogen) supplemented with 2\% FCS (Invitrogen), $2 \mathrm{~mm}$ L-glutamine (Invitrogen), $0.1 \mathrm{~mm}$ nonessential amino acids (Invitrogen), $1 \mathrm{~mm}$ sodium pyruvate (Invitrogen), $50 \mu \mathrm{M}$ 2-mercaptoethanol (SigmaAldrich), and $100 \mathrm{U} / \mathrm{ml}$ penicillin and $100 \mu \mathrm{g} / \mathrm{ml}$ streptomycin (Invitrogen). Cells were cultured at $37^{\circ} \mathrm{C}$ in $100 \%$ humidity and $5 \% \mathrm{CO}_{2}$ in the presence concentrations of $\mathrm{MBP}_{68-82}(20 \mu \mathrm{g} / \mathrm{ml})$ for $72 \mathrm{~h}$. As a control for proliferation, PHA $(10 \mu \mathrm{g} / \mathrm{ml})$ (Sigma-Aldrich) and without any stimulant were also performed. The splenocytes pulsed with $0.5 \mu \mathrm{Ci} /$ well of $\left[{ }^{3} \mathrm{H}\right]$ thymidine (Amersham Pharmacia Biotech, Orsay, France) $18 \mathrm{~h}$ before harvested on glass-fiber filters using a Tomtec 96-well cell harvester (Tomtec, Orange, CT, U.S.A.), and counted in a liquid scintillation counter (model 1205 Betaplate; Pharmacia-Wallac OY, Turku, Finland). Results obtained from triplicate cultures were expressed as mean cpm \pm S.D. and stimulation index (SI) \pm S.D. Meanwhile, splenocytes were cultured in 24-well plates at a concentration of $5 \times 10^{6}$ cells $/ \mathrm{ml}$. The cells were then stimulated in vitro with $\mathrm{MBP}_{68-82}(20 \mu \mathrm{g} / \mathrm{ml})$, PHA $(10 \mu \mathrm{g} / \mathrm{ml})$, or without any stimulants for $48 \mathrm{~h}$. Each treatment was performed in triplicate. At the end of the $48 \mathrm{~h}$ incubation period, supernatants were collected and used for the measurement of cytokines. Cytokines (TNF- $\alpha$ and IFN- $\gamma$ ) were detected in culture supernatants using commercially available Rat ELISA kits (eBioscience Ready-SET-Go, San Diego, CA, U.S.A.) according to manufacturer's instructions. Absorption read at $450 \mathrm{~nm}$ using an enzyme-linked immunosorbent microplate reader (Bio-Rad, Richmond, CA, 
U.S.A.; Model 2550). Standard curves for each assay were generated and the concentration of the cytokines in the cell supernatants was determined by extrapolation from the appropriated standard curve. The lower limit of detection for each assay was $8.0 \mathrm{pg} / \mathrm{ml}$ for TNF- $\alpha$ and $15.0 \mathrm{pg} / \mathrm{ml}$ for IFN$\gamma$. Standard curves for each assay were generated using recombinant rat cytokines (TNF- $\alpha$, IFN- $\gamma$; eBioscience), and the concentration of the cytokines in the cell supernatants was determined by extrapolation from the appropriate standard curve.

Assays for Cytokine Protein Levels The rats $(n=6$, per group) were treated with SIN $(50 \mathrm{mg} / \mathrm{kg}, 100 \mathrm{mg} / \mathrm{kg}$ or $200 \mathrm{mg} / \mathrm{kg}$, respectively) by i.p. for 5 consecutive days (day -1 to day 3 ). Animals were sacrificed for molecular analysis at postonset day 4. Cytokine protein levels were examined by ELISA. Spinal cord samples were prepared by homogenization in ice-cold PBS supplemented with protease inhibitor cocktail (Sigma-Aldrich) using a tissue-tearor homogenizer (Cole-Parmer Instrument, IL, U.S.A.). The samples were then centrifuged for $15 \mathrm{~min}$ at $4000 \mathrm{rpm}$ to separate extracellular supernatant from the cell pellet. Aliquots of supernatant were prepared and stored at $-80^{\circ} \mathrm{C}$ until cytokines assays were performed. Levels of TNF- $\alpha$ and IFN- $\gamma$ were assayed using ELISA kits from eBioscience. The concentration of the cytokines in the cell supernatants was determined by extrapolation from the appropriate standard curve. Total protein was determined using the BCA assay (Pierce, Rockford, IL, U.S.A.). Cytokine content was then expressed as $\mathrm{pg} / \mathrm{mg}$ total protein.

Chemokines mRNA Detection by RT-PCR Animals ( $n=6$, per group) were sacrificed for molecular analysis at postonset day 4 . The spinal cords were removed and frozen in liquid nitrogen, then stored at $-80^{\circ} \mathrm{C}$ until ready for use. The tissues were subsequently homogenized in $700 \mu \mathrm{l}$ of a guanidinium isothiocyanate solution containing $49 \mu \mathrm{l}$ mercaptoethanol using a tissue-tearor homogenizer (Cole-Parmer Instrument). Total RNA was extracted by using the Absolutely RNA ${ }^{\mathrm{TM}}$ RT-PCR Miniprep Kit (STRATAGENE, La Jolla, CA, U.S.A.). The concentration of total RNA in the final elutes was determined by spectrophotometer.

For cDNA synthesis, a master solution was prepared by mixing $2 \mu \mathrm{l}$ oligo-Primers $(0.1 \mathrm{mg} / \mathrm{ml}), 8 \mu \mathrm{l}$ of $5 \times$ firststrand buffer (Promega, Madison, WI, U.S.A.), $4 \mu$ l of dithiothreitol $(0.1 \mathrm{~m})$ (Promega), $4 \mu \mathrm{l}$ of dNTP (Promega) $(2.5 \mathrm{~mm}), 0.5 \mu \mathrm{l}$ of RNasin ribonuclease inhibitor (Promega) $(40 \mathrm{U} / \mu \mathrm{l})$ and $2 \mu \mathrm{l}$ of RQ1 RNase-free DNAse (Promega) $(2 \mathrm{U} / \mu \mathrm{l})$. Two micrograms of total RNA dissolved in $0.1 \%$ diethypyrocarbonate (DEPC, Invitrogen)-treated water was reverse-transcribed. The mixture was incubated at $37^{\circ} \mathrm{C}$ for $30 \mathrm{~min}$, thereafter for $5 \mathrm{~min}$ at $65^{\circ} \mathrm{C}$ to inactivate the DNAse. The reverse transcription reaction was started by adding $1 \mu \mathrm{l}$ of RNasin ribonuclease inhibitor $(40 \mathrm{U} / \mu \mathrm{l})$ and $1 \mu \mathrm{l}$ of MMLVreverse transcriptase (Promega) $(200 \mathrm{U} / \mu \mathrm{l})$. The mixture was incubated at $42^{\circ} \mathrm{C}$ for $1 \mathrm{~h}$ and then the reaction was stopped by incubated at $95^{\circ} \mathrm{C}$ for $10 \mathrm{~min}$.

PCR amplification was performed in a reaction volume of $50 \mu \mathrm{l}$ containing $2 \mu \mathrm{l}$ of cDNA product and HotStarTaq ${ }^{\mathrm{TM}}$ DNA polymerase (Qiagen, Germany) using PTC-200 Peltier Thermal Cycler (MJ Research, Waltham, MA, U.S.A.). Amplification of the constitutively expressed enzyme D-glyceraldehyde-3-phosphate dehydrogenase (GAPDH) was used as an internal control to assess the reverse transcription efficiency. The oligonucleotide primers used were: 5'-CATCCCTCACCGTCATC-3' (sense) and 5'-CCTCTCTGGGTTGGCAC-3' (antisense) for RANTES; The oligonucleotide primers used were: 5'-AAGAAGCTGTAGTATTTGTCACCAAGCTCA-3' (sense) and 5'-CATCAGGTACGATCCAGGCT-3' (antisense) for MCP-1; 5'-GAAGGTCTCCACCACTGCCCTTGC-3' (sense) and 5'-TCAGGCATTCAGTTCCAGCTCAG-3' (antisense) for MIP-1 $\alpha$; and $5^{\prime}$-GTTCCAGTATGACTCTACCC-3' (sense) and 5'-ACTCTTCTGAGTGGCAGTGATGGC-3' (antisense) for GAPDH. The temperature cycling condition of amplification were as follows: for RANTES and GADPH, $15 \mathrm{~min}$ at $95^{\circ} \mathrm{C}$, then 25 cycles of $94^{\circ} \mathrm{C}$ for $40 \mathrm{~s}, 55^{\circ} \mathrm{C}$ for $40 \mathrm{~s}, 72^{\circ} \mathrm{C}$ for $60 \mathrm{~s}$, and a final extension at $72^{\circ} \mathrm{C}$ for $10 \mathrm{~min}$; for MCP-1, MIP- $1 \alpha$ and GADPH, $15 \mathrm{~min}$ at $95^{\circ} \mathrm{C}$, followed by 30 cycles of $94^{\circ} \mathrm{C}$ for $40 \mathrm{~s}, 58^{\circ} \mathrm{C}$ for $40 \mathrm{~s}, 72^{\circ} \mathrm{C}$ for $60 \mathrm{~s}$, and a final extension at $72^{\circ} \mathrm{C}$ for $10 \mathrm{~min}$. The amplification products were electrophoresed on $1.5 \%$ agarose gel, visualized by ethidium bromide staining, and photographed. Gel images were scanned using an image analysis system (Gel Doc ${ }^{\mathrm{TM}}$ XR170-8170; Bio-Rad, Hercules, CA, U.S.A.). The intensities of specific PCR bands were quantitated in relation to GAPDH bands amplified from the same cDNA using Quantity One (Bio-Rad).

Statistical Analysis Analysis were performed using Mann-Whitney $U$ test (for unpaired 2-group analysis) and one-way ANOVA test (for analysis of 3 or more groups). Results are expressed as mean \pm S.D.; $p$ values less than 0.05 were considered statistically significant.

\section{RESULTS}

Effect of SIN on the Clinical Signs of Rats We evaluated the ability of SIN $(50 \mathrm{mg} / \mathrm{kg}, 100 \mathrm{mg} / \mathrm{kg}$ or $200 \mathrm{mg} / \mathrm{kg}$, respectively) affecting induction and progression of EAE after immunization with $\mathrm{MBP}_{68-82}$. Treatment with SIN $(50 \mathrm{mg} / \mathrm{kg}, 100 \mathrm{mg} / \mathrm{kg}$ or $200 \mathrm{mg} / \mathrm{kg}$, respectively) was initiated prior to immunization (from day -1 to day 3 relative to immunization) for 5 consecutive days. SIN $(50 \mathrm{mg} / \mathrm{kg}$, $100 \mathrm{mg} / \mathrm{kg}$ or $200 \mathrm{mg} / \mathrm{kg}$, respectively) led to a statistically significant reduction in EAE clinical scores. These effects led to significant clinical improvement and delayed disease progression during the following $20 \mathrm{~d}$ of observation, indicating that SIN inhibited both development and progression of EAE (Fig. 2A, Table 1). At this time, loss of body weight, a characteristic feature of EAE that is correlated with disease severity (Figs. 2B, C). By contrast, treatment with daily dose of $200 \mathrm{mg} / \mathrm{kg}$ SIN was therapeutically effective in reducing the clinical manifestations of EAE and loss of body weight. Furthermore, these two parameters were significantly less severe for these two relevant criteria in rats given $50 \mathrm{mg} / \mathrm{kg}$ and $100 \mathrm{mg} / \mathrm{kg}$ SIN. The effect observed on the weight parameter, the most objective criteria, is not the result of a direct effect of the compound on weight gain because the molecule by itself does not affect the weight gain of normal rats (data not shown). SIN treatment led to a statistically significant reduction in EAE clinical score and percentage of initial body weight loss as well as a reduced number of inflammatory infiltrates (Fig. 2, Table 1). These effects led to significant clinical improvement and delayed disease progression during the following $20 \mathrm{~d}$ of observation (Fig. 2, Table 1). The plasma 
Table 1. Comparison of SIN Administration Doses on EAE Disease Progression ${ }^{a}$

\begin{tabular}{|c|c|c|c|c|c|c|c|}
\hline Group & Incidence $^{b)}$ & $\begin{array}{l}\text { Mean day } \\
\text { of onset }^{c}\end{array}$ & $\begin{array}{l}\text { Disease } \\
\text { index }^{d)}\end{array}$ & $\begin{array}{c}\text { Mean } \\
\text { maximun } \\
\text { severity }^{c)}\end{array}$ & $\begin{array}{c}\text { Body wt at } \\
\text { disease } \\
\left.(\% \text { of original })^{d}\right)\end{array}$ & $\begin{array}{c}\text { No. } \\
\text { inflammatory } \\
\text { Foci }^{c} \text { ) }\end{array}$ & $\begin{array}{l}\text { The plasma } \\
\text { concentration of } \\
\text { SIN }(\mu \mathrm{g} / \mathrm{ml})^{e)}\end{array}$ \\
\hline $0.2 \%$ DMSO & $20 / 20$ & $6.5 \pm 1.2$ & $1.9 \pm 0.4$ & $4.6 \pm 0.4$ & $70.4 \pm 5.0$ & $43.4 \pm 9.0$ & \\
\hline $\mathrm{SIN}(200 \mathrm{mg} / \mathrm{kg})$ & $15 / 20 *$ & $8.8 \pm 1.4 *$ & $0.5 \pm 0.2 *$ & $2.8 \pm 0.3^{*}$ & $84.5 \pm 5.0^{* *}$ & $12.5 \pm 7.0 *$ & $1.2 \pm 0.6^{*}$ \\
\hline $\mathrm{SIN}(100 \mathrm{mg} / \mathrm{kg})$ & $17 / 20$ & $7.5 \pm 1.8 *$ & $0.6 \pm 0.3 *$ & $3.4 \pm 0.4^{*}$ & $81.2 \pm 5.2 * *$ & $18.5 \pm 5.5^{*}$ & $3.4 \pm 0.9^{*}$ \\
\hline $\mathrm{SIN}(50 \mathrm{mg} / \mathrm{kg})$ & $19 / 20$ & $6.9 \pm 1.9$ & $0.9 \pm 0.6 *$ & $4.0 \pm 0.3$ & $73.4 \pm 4.8 * *$ & $25.5 \pm 8.5^{*}$ & $10.7 \pm 2.3^{*}$ \\
\hline
\end{tabular}

a) Lewis rats immunized with $\mathrm{MBP}_{68-82}$ (day 0 and day 2) and treated with different doses of SIN ( $50 \mathrm{mg} / \mathrm{kg}, 100 \mathrm{mg} / \mathrm{kg}$ or $200 \mathrm{mg} / \mathrm{kg}$, respectively) or $0.2 \%$ DMSO (as control group) by i.p. as described in Materials and Methods. b) Parameter of disease evaluated by Fisher's exact test (* $p=0.47)$. $c$ ) Parameter of disease evaluated by Kruskal-Wallis test ( $* p<0.05$ with post hoc analysis using Dunn's multiple comparison test). $d$ ) Parameter of disease evaluated by ANOVA ( $* p<0.05, * * p<0.001$ with $p o s t$ hoc analysis using Dunnett's multiple comparison test). e) After i.p. administration of SIN ( $50 \mathrm{mg} / \mathrm{kg}, 100 \mathrm{mg} / \mathrm{kg}$ or $200 \mathrm{mg} / \mathrm{kg}, n=10, \mathrm{per}$ group) or $0.2 \%$ DMSO to EAE rats with 5 consecutive days (day -1 to day 3 ), the plasma concentrations were measured at 250 min $\left(t_{1 / 2 \mathrm{E}}\right)$ on day 3 . (*p<0.05, significantly different among the various doses (oneway ANOVA with a SNK post hoc test). The group of $0.2 \%$ DMSO was not detected the concentration of SIN.

A
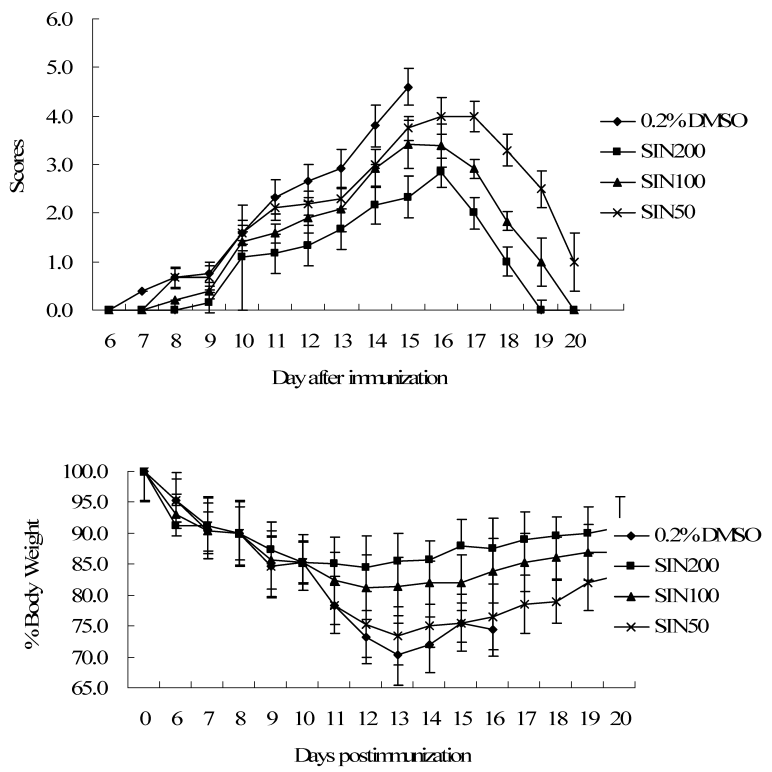

$\mathrm{C}$

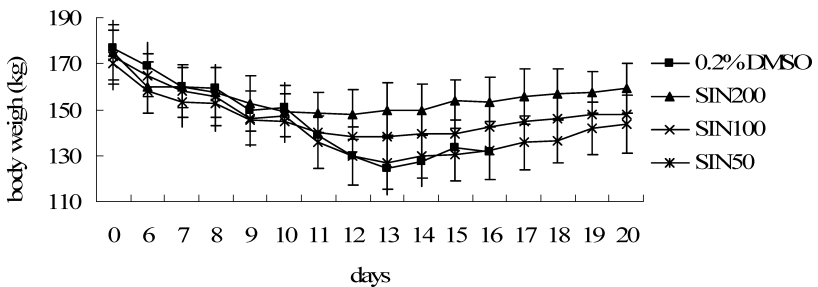

Fig. 2. Dose-Dependent Effects of SIN Treatment on EAE-Associated Disease Activity and Weight Loss

Female Lewis rats were immunized with injected s.c. into the two hind footpads of inoclulum containing $50 \mu \mathrm{g} \mathrm{MBP}_{68-82}$ with complete Freund's adjuvant on day 0 and day 2, animals received various doses of SIN $(50 \mathrm{mg} / \mathrm{kg}, 100 \mathrm{mg} / \mathrm{kg}$ or $200 \mathrm{mg} / \mathrm{kg}$, respectively) or $0.2 \%$ DMSO by i.p. for 5 consecutive days (day -1 to day 3 ). (A) Animals are scored daily for clinical symptoms on a $0-5$ predetermined scale. Mean clinical scores were determined from each treatment group $(n=20)$. (B) SIN reduces the change in the body weigh associated with EAE induction. The data are graphed as \% body weight to illustrate changes compared to the value for each animal at the experimental starting (C) SIN reduces the change in the body weigh associated with EAE induction. The data are graphed as body weight to illustrate changes compared to the value for each animal at the experimental starting.

concentrations of SIN $(50 \mathrm{mg} / \mathrm{kg}, 100 \mathrm{mg} / \mathrm{kg}$ or $200 \mathrm{mg} / \mathrm{kg}$, respectively) in EAE rats were detected (Table 1).

Effect of SIN on Inflammation in the Spinal Cord The neuropathological changes in EAE and MS are associated with the blood brain barrier breakdown and infiltration by mononuclear cells. In order to understand the mechanism of therapeutic efficiency in EAE, we studied the effect of SIN on the inflammation in the CNS in EAE model. EAE animals treated with SIN showed infiltration of the CNS by inflammatory cells but not to the extent as that seen in EAE animals (Fig. 3).

Effect of SIN Treatment on Peripheral T Cell Responses and Cytokines We examined whether SIN blockade could affect proliferation of $\mathrm{MBP}_{68-82}$-specific $\mathrm{T}$ cells in vitro. $\mathrm{T}$ cell response to $\mathrm{MBP}_{68-82}$ peptide was tested on splenocytes taken from all groups of treated mice $7 \mathrm{~d}$ after immunization and cultured in the presence of $\mathrm{MBP}_{68-82}$ $(20 \mu \mathrm{g} / \mathrm{ml})$. T cells derived from SIN-treated showed a significant reduction in proliferation (Figs. 4A, B), whereas no difference was observed when $\mathrm{T}$ cells were stimulated in parallel with $0.2 \%$ DMSO. The cytokine TNF- $\alpha$ and IFN- $\gamma$ are believed to be important modulators of disease activity of MS. We asked whether EAE protection was associated with an immune response characterized by considerable cytokine switching. The production of TNF- $\alpha$ and IFN- $\gamma$ was significantly reduced by SIN treatment in the presence of $\mathrm{MBP}_{68-82}$ (Figs. 4C, D).

Effect of SIN Treatment on Expression of Chemokines and Cytokines of the Spinal Cord In order to determine whether the observed effects of SIN could be ascribed to the established cytokine modulating properties of this drug, we analyzed TNF- $\alpha$ and IFN- $\gamma$ levels in the spinal cords of EAE-induced rats treated with SIN $(50 \mathrm{mg} / \mathrm{kg}, 100 \mathrm{mg} / \mathrm{kg}$ or $200 \mathrm{mg} / \mathrm{kg}$, respectively) in comparison with DMSO-treatment EAE rats ( $n=6$, per group) (Fig. 5). Following EAE induction and treatment with either SIN or DMSO alone on the day prior to immunization the spinal cords were harvested on the $4 \mathrm{~d}$ after onset and prepared for analysis of cytokines TNF- $\alpha$ and IFN- $\gamma$. The level changes were determined in tissues taken from a separate set of animals at the same day 4 post-onset time point. ELISA was used to establish TNF- $\alpha$ and IFN- $\gamma$ amounts. TNF- $\alpha$ was decreased $33.1 \%$ in the spinal cords of SIN $200 \mathrm{mg} / \mathrm{kg}$-treated rats with a mean of $(13.6 \pm 3.2) \mathrm{pg} / \mathrm{mg}$ and $23.2 \%$ in the spinal cords of SIN $100 \mathrm{mg} / \mathrm{kg}$-treated rats with a mean of $(15.6 \pm 4.2) \mathrm{pg} / \mathrm{mg}$ compared with $(20.3 \pm 2.3) \mathrm{pg} / \mathrm{mg}$ in DMSO-treatment EAE rats $(p=0.033,0.041$, respectively). There was no difference between the level of TNF- $\alpha(18.55 \pm 3.5) \mathrm{pg} / \mathrm{mg}$ in SIN $50 \mathrm{mg} / \mathrm{kg}$-treated rats and that in DMSO-treatment EAE rats $(p=0.063)$ (Fig. 5). IFN- $\gamma$ was decreased $58.3 \%$ in SIN 

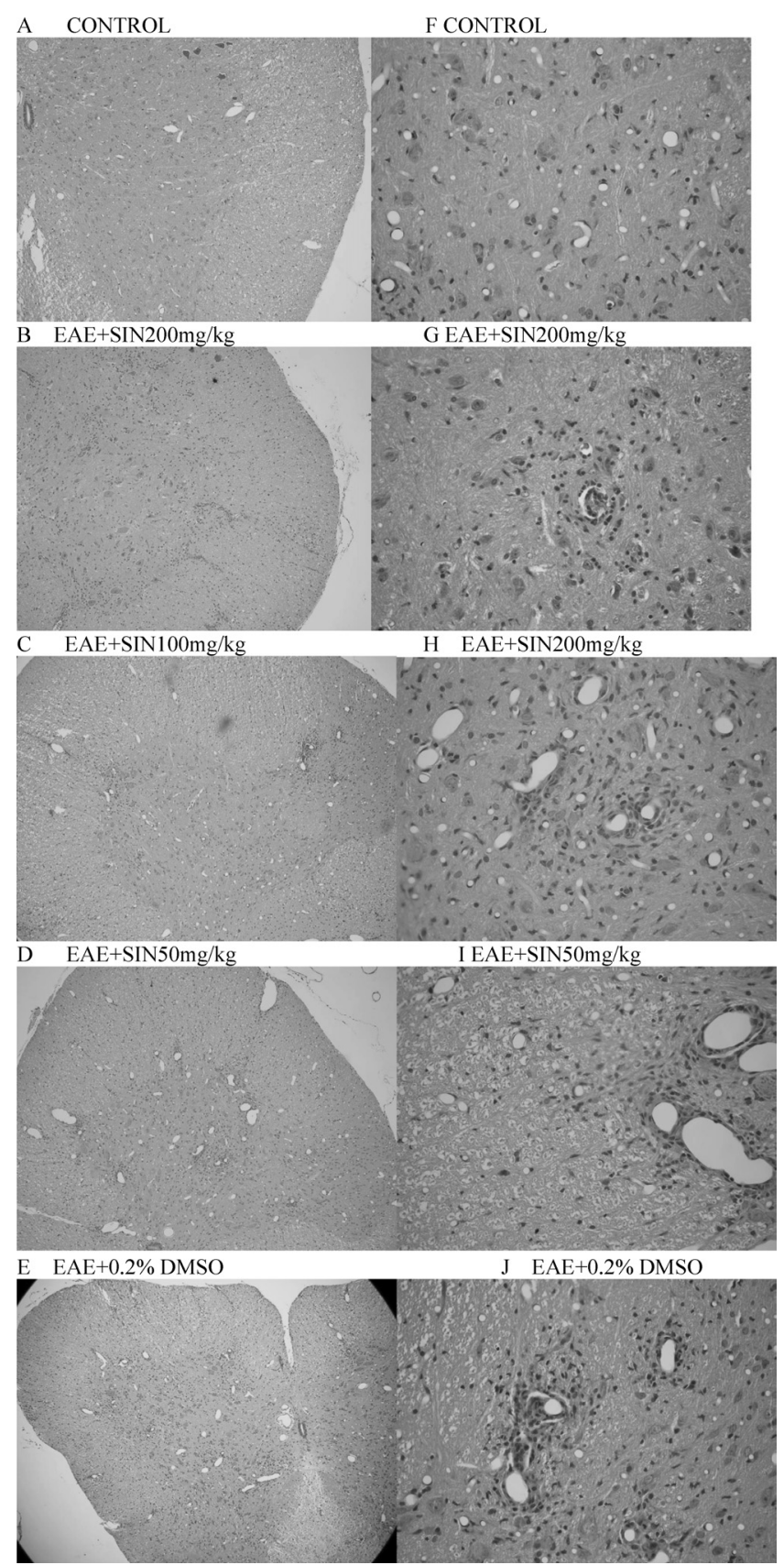

Fig. 3. The Down-Regulatory Effect of SIN on the Lumber Spinal Cord of EAE Rats

Inflammation in section of lumbar spinal cords from EAE $+0.2 \%$ DMSO $(n=20)$ and EAE + various SIN $(50 \mathrm{mg} / \mathrm{kg}, 100 \mathrm{mg} / \mathrm{kg}$ and $200 \mathrm{mg} / \mathrm{kg}, n=20$ per group) Lewis rats at the day -1 for 5 consecutive days after immunized. The lumber spinal cord sections were performed $4 \mathrm{~d}$ after disease onset, near the peak of clinical activity, and fixed in $10 \%$ formalin. Paraffin-embedded sections of $4 \mu \mathrm{m}$ thickness were cut and stained with H\&E. Sections from 4-10 segments per rat were examined blindly for the number of inflammatory foci by using a previously published scoring system. Spinal cords from SIN-treated rats show lesser dense mononuclear infiltration (H\&E) surrounding vascellum (B, C, D, G, H, I). Spinal cords from 0.2\% DMSO-treated EAE rats show diffuse dense mononuclear infiltration surrounding vascellum (E, J). Spinal cord from Magnification: A, B, C, D, E×100; F, G, H, I, J×400.

$200 \mathrm{mg} / \mathrm{kg}$ rats with $(658.9 \pm 95.1) \mathrm{pg} / \mathrm{mg}, 45.3 \%$ in SIN 100 $\mathrm{mg} / \mathrm{kg}$ with $(863.4 \pm 50.7) \mathrm{pg} / \mathrm{mg}$ and $11.8 \%$ in SIN $100 \mathrm{mg} / \mathrm{kg}$ rats with $(1391.7 \pm 74.1) \mathrm{pg} / \mathrm{mg}$ with a mean of $(1578.4 \pm$ $40.0) \mathrm{pg} / \mathrm{mg}$ ( $p=0.002,0.0017,0.008$, respectively).

These findings support the previously characterized functions of SIN in down-regulating the expression of key Th1 inflammatory cytokines and suggest that the ability of SIN to
A

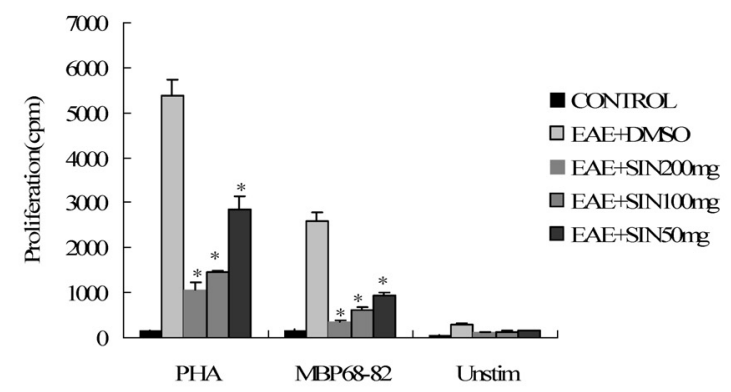

B

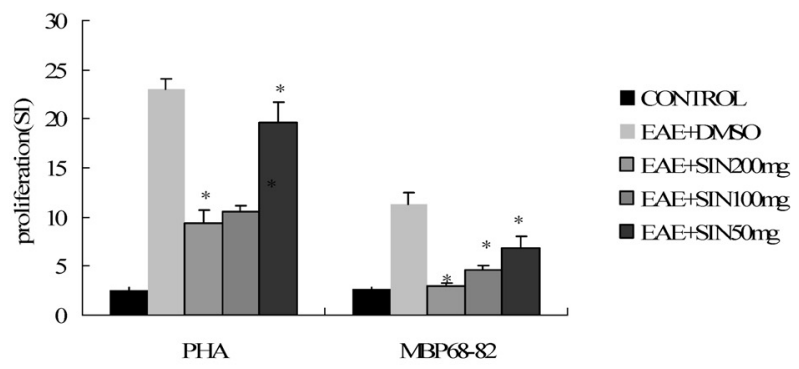

C

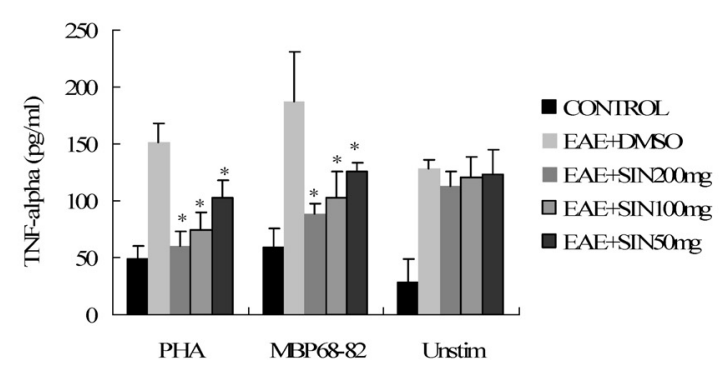

$\mathrm{D}$

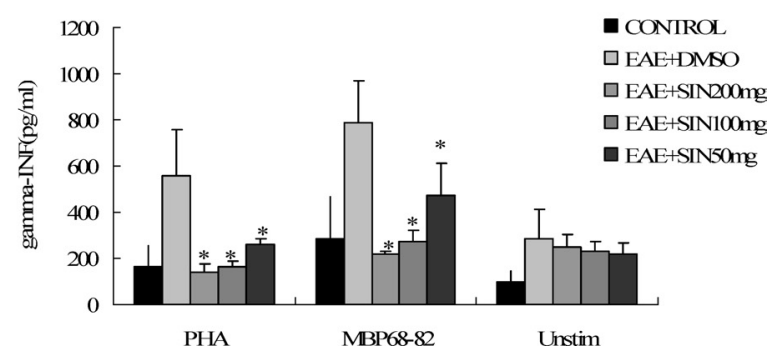

Fig. 4. Effect of SIN Treatment on Proliferation Assay and Cytokine Levels in Vivo

EAE animals are analyzed at day 7 after immunization. In vivo $\mathrm{SIN}(50 \mathrm{mg} / \mathrm{kg}$, $100 \mathrm{mg} / \mathrm{kg}$ or $200 \mathrm{mg} / \mathrm{kg}$, respectively) inhibits proliferation and production of TNF- $\alpha$ and INF- $\gamma$ of splenocytes when stimulated with the myelin antigen $\mathrm{MBP}_{68}$ $(20 \mu \mathrm{g} / \mathrm{ml})$, PHA $(10 \mu \mathrm{g} / \mathrm{ml})$ or without any stimulants. (A, B) SIN treatment inhibit the proliferation of splenocytes stimulated with $\mathrm{MBP}_{68-82}$ or PHA in dose-dependent manner $(* p<0.05$ with post hoc analysis using Dunn's multiple comparison test). (C, D) TNF- $\alpha$ and INF- $\gamma$ secretion of splenocytes are inhibited by SIN treatment when splenocytes were stimulated with the myelin antigen $\mathrm{MBP}_{68-82}$ or PHA in dose-dependent manner $(* p<0.05$ with post hoc analysis using Dunn's multiple comparison test)

reduce disease activity in the EAE model at the clinical level relying on this mechanism of action.

The CC chemokines, including CCL5/regulated on activation normal T-cell expressed and secreted (RANTES), CCL2/monocyte chemotactic protein (MCP)-1 and CCL3/ macrophage inflammatory protein (MIP)- $1 \alpha$ are efficient 
chemoattractants for Th1. $\left.{ }^{13}\right)$ The mRNA levels of these chemokines have been identified and quantified in the spinal cords both of SIN-administered and control DMSO-administered rats by the RT-PCR method. Expression of these chemokines was dramatically reduced in the spinal cords in SIN-treated rats, whereas very little reduction was seen in control DMSO-administered rats (Fig. 6).

\section{DISCUSSION}

MS is one of the most common chronic and disabling disorders of the CNS. Despite the availability of several immunomodulatory and immunosuppressive drugs on the market, these have only been demonstrated moderate effectiveness, and efficient treatments for MS patients are still desperately needed. ${ }^{17)}$ Based on its similarities with MS, EAE is
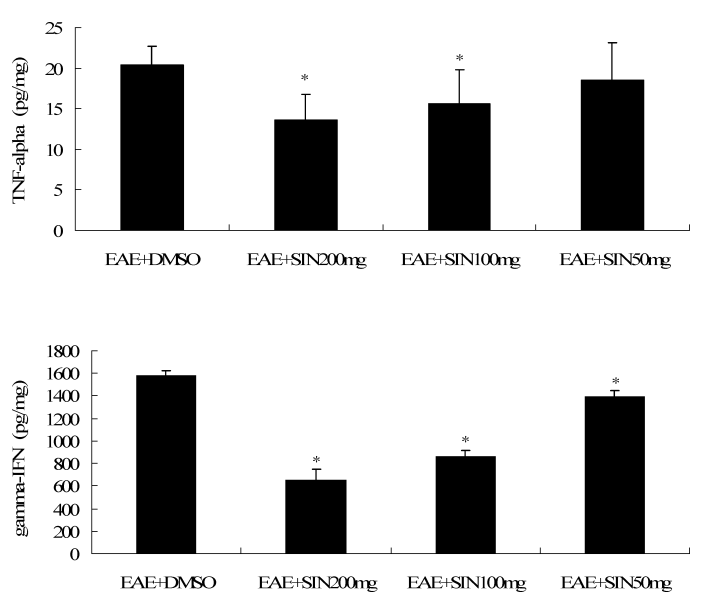

Fig. 5. Effect of SIN Treatment on Cytokine Protein Levels in Spinal Cord

Cytokine levels in spinal cords from SIN-treated ( $n=6$, per group) and DMSO-treat $(n=6)$ EAE animals are analyzed at day 4 post-onset. TNF- $\alpha$ and IFN- $\gamma$ levels are determined by ELISA. Protein concentrations expressed as mean $\mathrm{pg} / \mathrm{mg}$ with error bars indicating S.D. for ELISA $(* p<0.01$ with post hoc analysis using Dunn's multiple comparison test). useful for preclinical test of agents to be considered for treatment of this human inflammatory demyelinating disease. In the present study, we have demonstrated that SIN, an antirheumatic alkaloid, derived from the Chinese medicinal plant, effectively suppresses the development of EAE in the monophasic acute Lewis rat model. The beneficial effect on disease activity was observed in the reduction of both incidence and severity, which correlated with decreased infiltration of inflammatory leukocytes and a modulation of cytokines and chemokines expression profiles. Together these data demonstrate that SIN has potent therapeutic effects on autoimmune-mediated inflammatory pathologies in the CNS.

SIN, derived from the stem of medical plant Sinomenium acutum, is a purified bioactive alkaloid, and its oral dosage form has been approved by the State Food and Drug Administration of China as a botanical product in treating rheumatic and arthritic diseases. A series of pharmacological studies on its anti-inflammatory, anti-arthritic, analgesic and immunosuppressive effects had been investigated. ${ }^{3-5,14,18-20)}$ The plasma concentration of SIN is increased with the increase of dose administration, which may be a positive associate with the clinical neurological score of EAE rat from our data. Furthermore, SIN i.p. given at $200 \mathrm{mg} / \mathrm{kg}$ could induce adverse effects in the animals manifested as dyspnea, and those adverse effects were observed at the early time period, usually around $15 \mathrm{~min}$ after drug administration.

Treatment experiments indicate that SIN is effective when administered on the day prior to disease onset (Fig. 2). Although we did not directly test the ability of SIN to ameliorate disease symptoms at the peak of disease severity, our findings suggest that this drug is capable of suppressing a pre-activated immune system in the early effector phase leading into disease onset. This timepoint relates to the early stage of disease onset in which antigen-specific $\mathrm{T}$ cells active or autoreactive $\mathrm{T}$ cell activation. ${ }^{21,22)}$ The stage of antigenspecific $\mathrm{T}$ cells activation is critical for inducing the relapse of MS. These processes rely on the secretion of TNF- $\alpha$ and IFN- $\gamma$ and are likely to be modulated by SIN. Histological

A
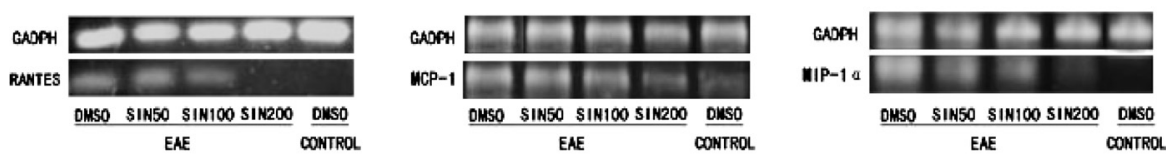

B

mRNA level analysis of integral EAE chemokines

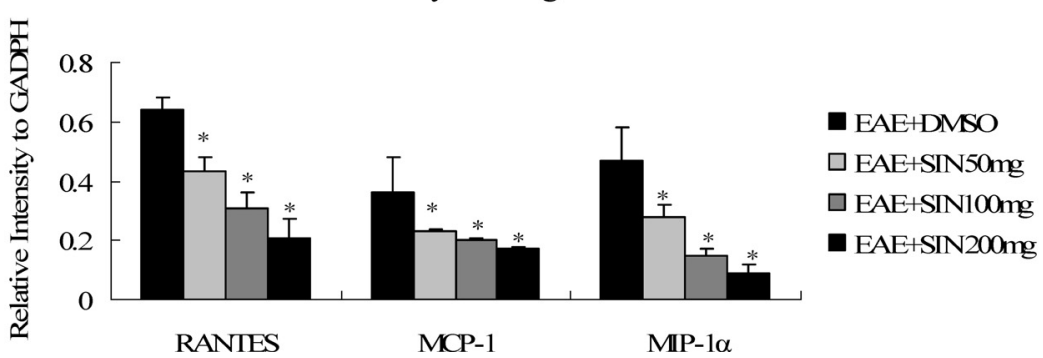

Fig. 6. RT-PCR for RANTES, MCP-1 and MIP- $1 \alpha$ mRNAs in the Spinal Cords of the EAE Lewis Rat on the $4 \mathrm{~d}$ after Onset

(A) Representative data show the intensity of RT-PCR products obtained from spinal cord samples in each group. Compared with control rats, mRNA expression for RANTES, MCP-1 and MIP-1 $\alpha$ decrease in the SIN-treated rats. (B) The intensity of each band is calculated using Kodak Digital Science 1D image analysis software. The relative quantities of the genes are presented as the ratio of intensities of RANTES, MCP-1 and MIP- $1 \alpha$ bands against GADPH. Data are representative of three independent experiments and indicate the mean ratio of triplicate results in each experiment. 
examination in our study supports this hypothesis with a substantial reduction in the number of perivascular infiltrates observed in the SIN-treated EAE animals (Fig. 3).

The dose-response experiments carried out in this study demonstrated that SIN was therapeutic at all doses tested and was very effective even at middle doses when administered topically (Table 1 ). SIN at $100 \mathrm{mg} / \mathrm{kg}$ was only moderately less effective than at $200 \mathrm{mg} / \mathrm{kg}$ and less adverse effects. However, SIN at a dose of $50 \mathrm{mg} / \mathrm{kg}$ was less effective than that of $100 \mathrm{mg} / \mathrm{kg}$. The $100 \mathrm{mg} / \mathrm{kg}$ dose of SIN was considered optimal for subsequent experiments as the lowest efficacious dose that also correlated well with a reduction in EAEinduced body weight loss (Figs. 2B, C), which may be another indicator of recovery.

The ability of SIN to modulate cytokine expression profiles in the EAE model was confirmed by significant reductions in both TNF- $\alpha$ and IFN- $\gamma$ observed at the day 4 postonset timepoint (Fig. 4). However, this timepoint is well beyond the administration time of SIN and cytokine profiles may simply reflect the fewer number of infiltrating cells demonstrated in the histological evaluation (Fig. 3). In order to discern a more precise mechanism of action, examination of earlier timepoints will be required. This cytokine has been implicated in resolution of disease activity and demonstrated direct effects on TNF- $\alpha$ and IFN- $\gamma$ expression. ${ }^{23)} \mathrm{EAE}$ in the Lewis rat is characterized by extensive mononuclear cell inflammation predominantly in the spinal cord, brain stem, and cerebellum with spontaneous recovery after $5-7 \mathrm{~d}^{24)}$ IFN- $\gamma$ and TNF- $\alpha$ are also inhibited in the CNS of EAE animals treated with SIN. As a consequence, inhibition of IFN- $\gamma$ expression in SIN treated animals could in turn result in the reduced expression of MHC II molecules thereby inhibiting the proliferation of T-lymphocytes as has been shown with statins, ${ }^{25)}$ copolymer $^{26)}$ and IFN- $\beta .^{27)}$

Chemokines are divided into two major subfamilies based on the spacing of the first pair of $\mathrm{N}$-terminal cysteine residues. This molecular subdivision generally correlates with function. The $\mathrm{CXC}$ chemokines usually recruit neutrophils, whereas $\mathrm{CC}$ chemokines tend to attract monocytes. The CC chemokines are involved in the pathogenesis of immune-mediated inflammation through monocyte-macrophage activation and recruitment. ${ }^{28)}$ The $\mathrm{CC}$ chemokines, including RANTES, MCP-1 and MIP- $1 \alpha$ are efficient chemoattractants for Th1. ${ }^{29)}$

In EAE, inflammation is associated with infiltration by $\mathrm{T}$ cells and monocytes and is restricted to spinal cord. In our studies, we have shown the expression of chemokines in the spinal cord during the peak of disease. We showed that three chemokines-RANTES, MCP-1 and MIP- $1 \alpha$ that act toward $\mathrm{T}$ cells and monocytes were upregulated simultaneously. The expression of $\mathrm{CC}$ chemokines involved in Th1 cell type attraction correlated with the expression of their receptors, which suggests a role for these chemokines in the pathogenicity of EAE. ${ }^{30,31)}$ Our results support that RANTES, MCP-1, and MIP- $1 \alpha$ are significantly increased in the spinal cords and correlated with the clinical severity of the disease. Administration of SIN decrease the mRNA levels of these chemokines and delay onset, suppress the development of disease and clinical severity of EAE.

In conclusion, our findings demonstrate that SIN has beneficial effects on the Lewis rat model of EAE and suggest its potential use as a therapeutic agent for prevention the relapse of MS. We believe that antirheumatic alkaloid SIN as an immunomodulatory is well suited for a complex inflammatory disease such as MS.

Acknowledgment This work was supported by Science Fund of Health Department of Jiangsu Province (H200504).

\section{REFERENCES}

1) Wong K. C., Wu L. T., "History of Chinese Medicine," 2nd ed., Shanghai, China, 1936, p. 119.

2) Ke X. Y., Xiu M. X., Beijing Yixue, 3, 186-187 (1986).

3) Liu L., Buchner E., Beitze D., Schmidt-Weber C. B., Kaever V., Emmrich F., Kinne R. W., Int. J. Immunopharmacol., 18, 529-543 (1996).

4) Liu L., Resch K., Kaever V., Int. J. Immunopharmacol., 16, 685-691 (1994).

5) Feng H., Yamaki K., Takano H., Inoue K. I., Yanagisawa R.,Yoshino S., Planta Med., 72, 1383-1388 (2006).

6) Alvord E. C., Jr., Shaw C. M., Hruby S., Ann. Neurol., 6, 469-473 (1979).

7) Lalive P. H., Schluep M., Chofflon M., Du Pasquier R., Rev. Med Suisse, 2, 1166-1168, 1170 (2006).

8) Zamvil S. S., Steinman L., Annu. Rev. Immunol., 8, 579-621 (1990).

9) Bourrie B., Bribes E., Esclangon M., Garcia L., Marchand J., Thomas C., Maffrand J. P., Casellas P., Proc. Natl. Acad. Sci. U.S.A., 96, 12855-12859 (1999).

10) Hashim G. A., Science, 196, 1219-1221 (1977)

11) Mannie M. D., Paterson P. Y., U'Prichard D. C., Flouret G., Proc. Natl. Acad. Sci. U.S.A., 82, 5515-5519 (1985).

12) Pashov A., Bellon B., Kaveri S. V., Kazatchkine M. D., Mult. Scler, 3, $153-156$ (1997).

13) Ohta Y., Fukuda S., Makino H., Immunopharmacology, 37, 167-174 (1997).

14) Liu Z. Q., Chan K., Zhou H., Jiang Z. H., Wong Y. F., Xu H. X., Liu L., Life Sci., 77, 3197-3209 (2005).

15) De Rosa V., Procaccini C., La Cava A., Chieffi P., Nicoletti G. F., Fontana S., Zappacosta S., Matarese G., J. Clin. Invest., 116, 447-455 (2006).

16) Stosic-Grujicic S., Savic-Radojevic A., Maksimovic-Ivanic D., Markovic M., Bumbasirevic V., Ramic Z., Mostarica-Stojkovic M., J. Neuroimmunol., 130, 66-77 (2002).

17) Hemmer B., Nessler S., Zhou D., Kieseier B., Hartung H. P., Nat. Clin. Pract. Neurol., 2, 201-211 (2006).

18) Li X. J., Yue P. Y., Ha W. Y., Wong D. Y., Tin M. M., Wang P. X., Wong R. N., Liu L., Life Sci., 79, 665-673 (2006).

19) Liu J. H., Li W. D., Teng H. L., Lin Z. B., Yao Xue Xue Bao, 40, 127 131 (2005).

20) Liu Z. Q., Zhou H., Liu L., Jiang Z. H., Wong Y. F., Xie Y., Cai X., Xu H. X., Chan K., J. Ethnopharmacol., 99, 61-67 (2005).

21) Dore-Duffy P., Balabanov R., Rafols J., Swanborg R. H., J. Neurosci. Res., 44, 223-234 (1996).

22) Juedes A. E., Ruddle N. H., J. Immunol., 166, 5168-5175 (2001).

23) Matejuk A., Vandenbark A. A., Burrows G. G., Bebo B. F., Jr., Offner H., J. Immunol., 164, 3924-3931 (2000).

24) Willenborg D. O., J. Immunol., 123, 1145-1150 (1979).

25) Weber M. S., Youssef S., Dunn S. E., Prod'homme T., Neuhaus O., Stuve O., Greenwood J., Steinman L., Zamvil S. S., J. Neuroimmunol., 178, 140-148 (2006).

26) Illes Z., Stern J. N., Keskin D. B., Reddy J., Brosnan C. F., Waldner H., Santambrogio L., Kuchroo V. K., Strominger J. L., Eur. J. Immunol., 35, 3683-3693 (2005).

27) Schaefer C., Hidalgo T. R., Cashion L., Petry H., Brooks A., Szymanski P., Qian H. S., Gross C., Wang P., Liu P., Goldman C., Rubanyi G. M., Harkins R. N., J. Interferon Cytokine Res., 26, $449-454$ (2006).

28) Kennedy K. J., Strieter R. M., Kunkel S. L., Lukacs N. W., Karpus W. J., J. Neuroimmunol., 92, 98-108 (1998).

29) Kennedy K. J., Karpus W. J., J. Clin. Immunol., 19, 273-279 (1999).

30) Glabinski A. R., Tuohy V. K., Ransohoff R. M., Neuroimmunomodulation, 5, 166-171 (1998).

31) Dogan R. N., Karpus W. J., Front. Biosci., 9, 1500-1505 (2004). 